\title{
ARTICLE
}

\section{Results of neuromarketing study of visual attention and emotions of buyers in retail store environment}

Boldbaatar Gonchigjav*

Department of Business Administration, School of Business, University of the Humanities Ulaanbaatar, Mongolia

ARTICLE INFO: Received: 30 Mar, 2020; Accepted: 08 May, 2020

\begin{abstract}
Retail trade involves constant changes and trends due to influence of marketing promotions on traders themselves and their customers as well. This is an internal environment of a retail store, which is a part of factors that define customer's buying decision. In general, more than $80 \%$ of buyers make a buying decision on the spot or the last place where buyers normally can change their mind to make a purchase. A customer's final decision to make a purchase is affected not only by the cost of the item but also the means of marketing promotion and visual aspect of goods. Therefore, it is necessary to constantly collect factual information based on customers' feedback on effectiveness and efficiency of these marketing promotions in real-store environment. Recent trends of marketing research development demand a wide use of research methods in conducting in-store research based on new technologies besides the traditional ones. Optimal use of new methods of neuromarketing gives more opportunity to develop efficient marketing strategy and to provoke customers' interest and emotions as well. Techniques to stimulate customer's interest and emotions can help increase their motivation to make a purchase followed by increase in s store's sales and profit. In this study we have used a methodology based in neuromarketing technology to identify factors affecting customer's visual attention and emotions in a grocery store. The study was conducted in real environment of a retail grocery store using a mobile eye camera (Eye tracker), mobile electroencephalograph (EEG), face reading technology (FA) and internal position system. The objective of the study is to identify customers' reaction, emotions and feedback using selected neuromarketing methods in a store. At the end of the research, we have identified how neuromarketing techniques can be applied in better understanding customer behavior at a point of sale.
\end{abstract}

Keywords: neuromarketing; marketing promotion; Eye tracker; electroencephalograph; visual attention;

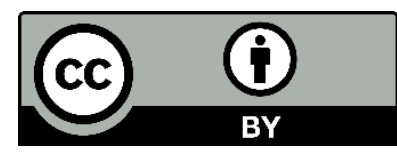

The Author(s). 2020 Open access This article is distributed under the terms of the Creative Commons Attribution 4.0 International License (https://creativecommons.org/licenses/by/4.0/), which permits unrestricted use, distribution, and reproduction in any medium, provided you give appropriate credit to the original author(s) and the source, provide a link to the Creative Commons license, and indicate if changes were made. 


\section{INTRODUCTION}

In recent times, trade organizations attach greater significance to their store environment and marketing promotions. The means to attract customers' visual attention and stimulate their emotions have been classified into several points of sale in terms of selling conditions and opportunities. Those stores, which do not belong to this classification yet, can become a priority in the future. To conclude, $75 \%$ of a buying decision is made at the point of sale, which proves the power of marketing promotion of the store [20]. The main goal of a store's marketing communication is to focus on promotion that leads to buyer's purchase decision [7]. POS (point of sale) continously uses marketing promotion materials, which include demo stands displaying different items, such as, store carts with different brand logos or ads for certain products [10]. In addition, customer feedback is significant for point of sale. Signs, posters, ads and other POP devices represent a certain aspect of a product that a customer needs. In this situation they provide a customer with necessary information [23]. In order to increase efficiency of this form of marketing promotion in a point of purchase (POP), it is important to differentiate the traditional stereotype among customers about POP (point of purchase) and POS (point of sale) [13].

\section{Theoretical background}

When a customer enters the shop, the interior should guide a customer through the shop and influence on his/her buying decisionmaking. The interior of the shop includes its organizational set-up, that is, layout in which all goods have specific place in a particular department, shop design, space for displaying products and specific items, advertising materials as well as labelling and prices of products [19]. In-store marketing promotion is a set of advertising media that are placed inside the shop. Their purpose is to inform and influence customers during their shopping. Consumer reactions influenced by marketing incentives (brands, products, advertising) and experiences with the consumption of these products result in a particular mental state. Unlike them, in this case (in-store marketing promotion), the object of interest of marketers and researchers is to measure the final purchasing interest and observe consumer behavior at the point of sale - what, where, when and for how much customers buy. There are a large number of measurable variables, such as perceived simplicity of finding products, overall impressions of the shop, visual attention and probability to return, but the final object of interest is shopping behavior [15].

\section{POP and POS materials}

"POP (Point of purchase) is a set of advertising materials and products used at the point of purchase for promoting a particular product or product range. This is the most important trigger of impulsive consumer shopping behaviour." "POS (Point of sale) includes materials used at the point of sale as part of the presentation of goods at the point of sale. They fulfill informative and sales support functions.'[13]. These means of marketing promotion are informational, they help consumers in making their purchasing decisions. People perceive them positively and pay considerable attention to them, which is a significant success. In everyday life we are in contact with moving pictures, texts or graphics. This complex of visual messages serves various purposes: inform, explain, instruct, persuade, teach, sell and entertain [12]. On the basis of these messages, the recipient forms an opinion, which depends on his/her abilities to select, process and integrate information from various sources. Human attention has a limited capacity, so for perceiving and processing information cognitively and in detail, a human being has to direct his/her full attention to the relevant information [12]. Perception is defined as "the process by which an individual selects, organizes and interprets stimuli into a meaningful and unified picture" [22]. Different people may perceive the same visual message differently and ascribe different meanings to it. The reason is that visual perception is active, 
exploratory, creative and highly selective. People filter what they perceive, they select various aspects based on their expectations, goals, knowledge and experiences [12].

\section{Perceptual and cognitive consumer process \\ Consumers have common visual} perception of objects and spatial vision. The ventral part of the brain (front part) primarily deals with information about objects structure, shape and colour, while the dorsal part (back part) deals with spatial vision, orientation and movement [24]. The next common feature is the so-called visual attention. Consumers, according to current needs, interests and goals, gradually focus their attention on actual essential aspects of the object and on small parts which they observe one by one [12]. We cannot forget about imagination, recalling images in consumer mind, as for example, when they remember the past, solve problems or read a book. This phenomenon could not be studied in the past, but at present it is possible to examine human mind using new technologies. Current research also notices eye movements when having images in mind [14]. According to Holsanova [12], aspects that may cause differences in visual perception are as follows: task or objective of research, knowledge and experiences, expectations, emotions and attitudes and cultural background of the consumer.

\section{Study of consumer behavior at the point of sale}

Consumer psychology and neuroscience offer more detailed study of consumer behaviour and decision-making process at the point of sale. Dolley [6] states that modern neuroscience has brought tools which help to see into human brains and open the way to the psychological process of decision-making black box of the brain. The concept of application of neuroscience methods in the study of consumer emotions and cognitive reactions has evoked a huge interest in recent years. In fact, the use of psycho-physiological techniques in consumer research is nothing new. Monitoring of dilated pupils and electro dermal activity was already practiced in the 1960s, which was later followed by eye tracking and measuring of cardiac activity [25]. Borta, Patнk and Postler [1] argue that for applying marketing in business, it is necessary to pay attention to human behaviour because shopping is a complex experience for human mind. Revolutionary new technologies provide unimaginable potential for the application of marketing and neuromarketing techniques. The retail market is changing at an incredible speed, therefore, many traders are trying to use innovative ideas to help them differ from their competitors [9]. Companies using sophisticated neuroscience research can reveal what affects their customers and what processes prevent buyer's decision. Accordingly, they choose an appropriate marketing strategy directly at the point of sale. In this regard, retailers have tools of merchandising and communication to attract the attention of customers, the so-called, POP and POS means [5]. Genco et al. [8] says there are three basic tasks that need to be fulfilled by each retail unit, to provide not only practical side of shopping but also the overall buyer experience. Nagyovo et al. [18] says that if we use neuromarketing research methods we understand consumer preferences concerning the purchasing decision. This idea continues with Popai [20] referring to the understanding of not revealed buyers motives through neuroscience principles. It also refers to the use of this information in creating marketing strategy in the shops. In the field of in-store marketing promotion, neuromarketing research is performed either in real conditions, directly in the shop, or in fictional space, where the environment of commercial shop is simulated. In research, the most commonly used method is EEG (electroencephalography), but eye tracking or cardiac, respiratory activity and recognition of emotions from micro-facial expressions [2] too are applied.

\section{Electroencephalography (EEG)}

Measurement of cortical electrical brain activity (activity of neurons in the upper part of the cerebral cortex) is still the most applied neuromarketing method in terms of cost and difficulty of executing individual research. The subject of this method is to examine the impact of incentives on changes of electrical brain 
activity of measured subjects. Electrodes applied to the scalp record 2000 times per second very low electrical current from particular brain fields generated by quick movement of neurons affected nerve impulses [2]. Frequent use of this technology in research, benefits from huge support of professional literature. The biggest limitation of EEG is that it is not possible to reliably measure changes in electrical activity deep inside the brain. There are static and mobile devices, usefulness of which partly differs depending on the number of channels. Each part of the brain is responsible for a specific function. The use of more affordable devices, which do not have sufficient number of sensors causes the lack of basic element of connection. And, in fact, there is the lack of results in terms of neurological recognized standards [21].

\section{Eye tracking (EOG)}

Measuring of eye movements and dilated pupils connected with the observation of object or scene has multiple uses in neuromarketing. It can be used as a separate tool, but also as an important complement to other indicators. Speed and changes of view direction provide valuable indicators of attention, interest and attraction. The tool used for measuring eye movements is called Eye Tracker, we recognize the mobile and stationary design of this device according to the research. According to Holmqvist et al. [11] we can describe four large classes of eye tracking measurements. Movement measurements are concerned with a whole variety of eye movements through space and the properties of these movements. Position measurements deal only with the properties of eye movements at spatial locations when a participant has or has not been looking. Numerosity measurements appertain to the number, proportion or rate of any countable eye movement event. Latency measurements

\section{MATERIALS AND METHODS}

Primary neuromarketing research of selected in-store marketing promotion tools was conducted in a supermarket of a traditional Mongolian retail chain. The impact of selected in-store marketing promotion tools on express the duration from the onset of one event to the onset of a second one. Measurements of this type also appear in the form of spatial distances.

\section{Facial expressions (FA)}

We can recognize a range of emotional states on a human face. Changes in facial expressions can be classified into two levels, observable changes of expression - microemotions (e.g. smile or scowl) and unobservable changes of mimic muscles (e.g. muscle contractions associated with positive and negative emotional responses). Observation of the facial expressions is found to be an important indicator of positive or negative emotional responses [18]. Special software (Face reader) can be used to detect observable changes in facial expressions, it can quickly detect emotions from recorded face of a tested subject. Micro-facial expressions are involuntary and fleeting facial expressions that reveal emotional experience of an individual. The seven basic facial expressions - happiness, sadness, anger, contempt, surprise, fear and disgust, can all be expressed [16]. Using these methods we can study the following:

- "attractive exterior of the shop (shopwindows, entrances, letterings),

- attractive interior of the shop (design, shop atmosphere, lighting),

- attractive merchandising and its tools (unloading, arrangements of goods, POP and POS means),

- consumer behaviour and decision at the point of sale.“ [18].

All can be reviewed by neuromarketing methods and benefit from its practical insights. Providing complex enjoyment of shopping that includes discovery, selection and payment can be made only when it is in accordance with conscious and subconscious buyer goals. [17].

customer's visual attention and emotions was recorded during an experiment in a real-store environment. It was recorded by neuromarketing method electroencephalograph (EEG) and biometric 
(somatic) method of recognizing emotions based on micro-facial expressions (Face Reader 6) done by the company MMDA. Visual attention was recorded using eye tracking by MMCG. Internal position system developed in collaboration with Nomin Company in
Ulaanbaatar was used for recording the location and time spent within specified departments of sales space. 21 respondents, aged 16 to 52 years, took part in the test distribution according to sex. (Table 1).

Table 1. Research sample

\begin{tabular}{|c|c|c|}
\hline & Absolute frequency & Relative frequency \\
\hline Male & 8 & $38.1 \%$ \\
\hline Female & 13 & $61.9 \%$ \\
\hline Total & 21 & $100.0 \%$ \\
\hline
\end{tabular}

The entire purchase was monitored during testing not only by internal position system but also by a Gopro Hero 3 camera located on the shopping cart opposite of tested participants. The record obtained from the camera was used to detect not only emotions from micro-facial expressions, but also to specify the results of position system. Special care was taken to ensure good illumination of the participant's face, which is an important requirement for Face Rader 6 to produce reliable results. Furthermore, we made sure that the participants were looking directly toward the camera while showing their facial expression. Although the software can handle rotations up to $40^{\circ}$, minimal rotation is desired to ensure optimal quality readings. The recordings with a resolution of 640480 at 25 frames per second were saved as AVI files and analyzed, frame-by-frame, with Face Reader 6 software, scaling the 7 basic emotions: happy, satisfied, surprised, neutral, sad, disgusted and angry. The "individual calibration" software feature was used for standardization. We used mobile electroencephalograph (EEG) and Emotive EPOC headset for data collection that describe emotional state of tested respondents in the store. Emotive EPOC headset consists of 14 data collecting electrodes and two reference electrodes placed and labelled in accordance with international 10-20 system of electrode layout. In this case, the most crucial data was obtained by software tool Affective Suite that records changes in emotions in real time. Every tested person had his/her unique profile in which data obtained was calculated according to certain personality traits. Subsequently, the sum of these differences was used for data normalization. The software recorded three main types of emotions: excitement, emotional engagement and frustration. Particular emotions were calculated on the basis of electrical activity recorded by electrodes necessary for the calculation of the given emotion. Groups of electrodes providing signals for the calculation of specific emotions can be seen in Table 2 .

Table 2. Electrodes necessary for the calculation of particular emotions

\begin{tabular}{|c|c|}
\hline Channels & Type of emotion \\
\hline F3, F4 & Frustration \\
\hline Not identified & Excitement \\
\hline O1, O2, F3, F4, F7, F8, FC5, FC6 & Engagement \\
\hline
\end{tabular}

For monitoring of eye movements, we used mobile eye camera (Eye Tracker). This device uses eye tracking technology Pupil Centered Corneal Reflection technology, whereas in this case it is a monocular system focused on the right eye with sampling rate of $30 \mathrm{~Hz}$. In order to analyze in detail the attraction of selected tools of marketing promotion at the point of purchase, we located IR Markers fixed to IR Markers Holders at the individual 
researched positions in a way that the IR sensor built in the front part of the Eye tracking glasses was able to differentiate signals transmitted from these miniature sensors.

For position measurement, internal position system was used, the accuracy of which was three meters. The system measures the speed, movement direction and position of shopping cart using a modified form of radio frequency identification RFID technology. On the basis of the data, motion maps of the buyer and time spent in particular sales departments were processed. Camera footage from Gopro 3 was used to specify critical data and the position, if necessary, was adjusted manually. Internal position system component deployment and reserved research area within store layout can be seen in Figure 1.

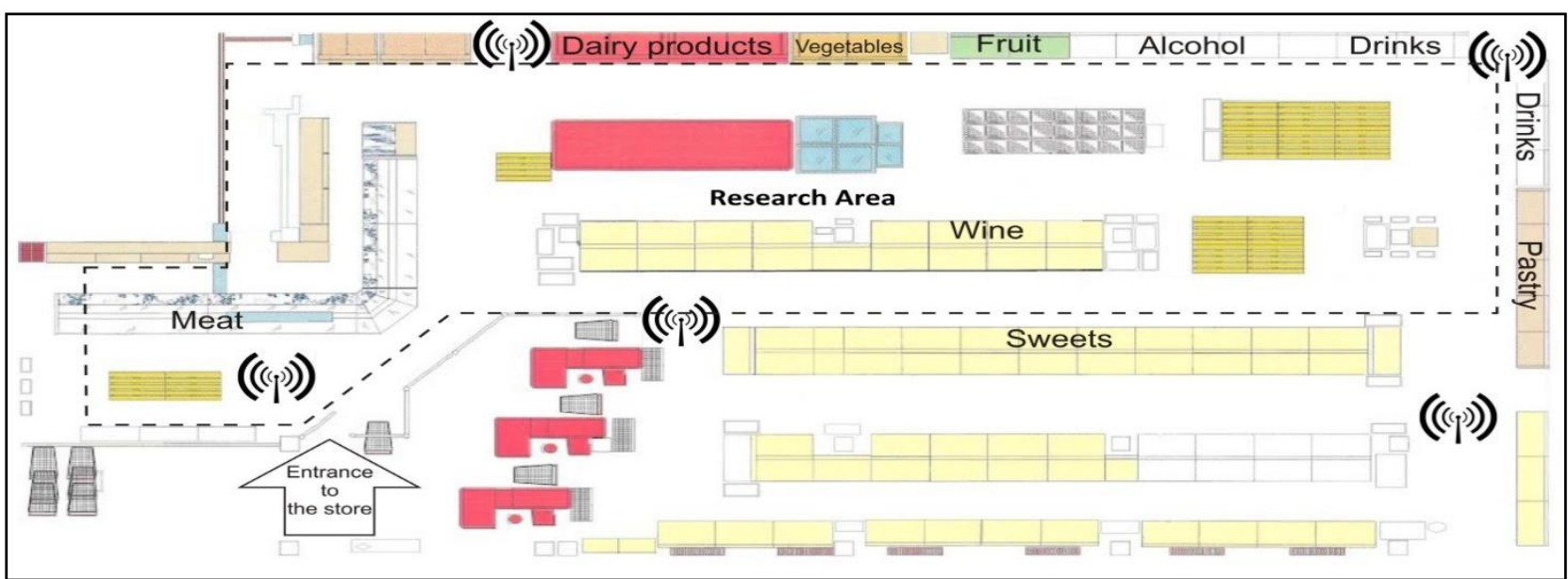

Figure 1. Internal position system component deployment and reserved research area

Primary data processing was carried out using descriptive statistics

(frequency, averages and standard deviations).

\section{RESULTS AND DISCUSSION}

In order to reveal consumer perception of particular in-store marketing promotion tools, the research was carried out in real conditions of a Nomin retail store in Ulaanbaatar, Mongolia. Customers participating in testing were asked to make a purchase in the previously reserved area of a retail store. The only condition was, except their own choice, to buy any goods from the department of dairy produce, pastry, sweets, wine, fruit and vegetables. The reason for this was that selected in-store marketing promotion tools were placed in the above mentioned departments. Based on the results of position system, the movements of tested subjects within the reserved area of supermarket can be seen in Figure 2.

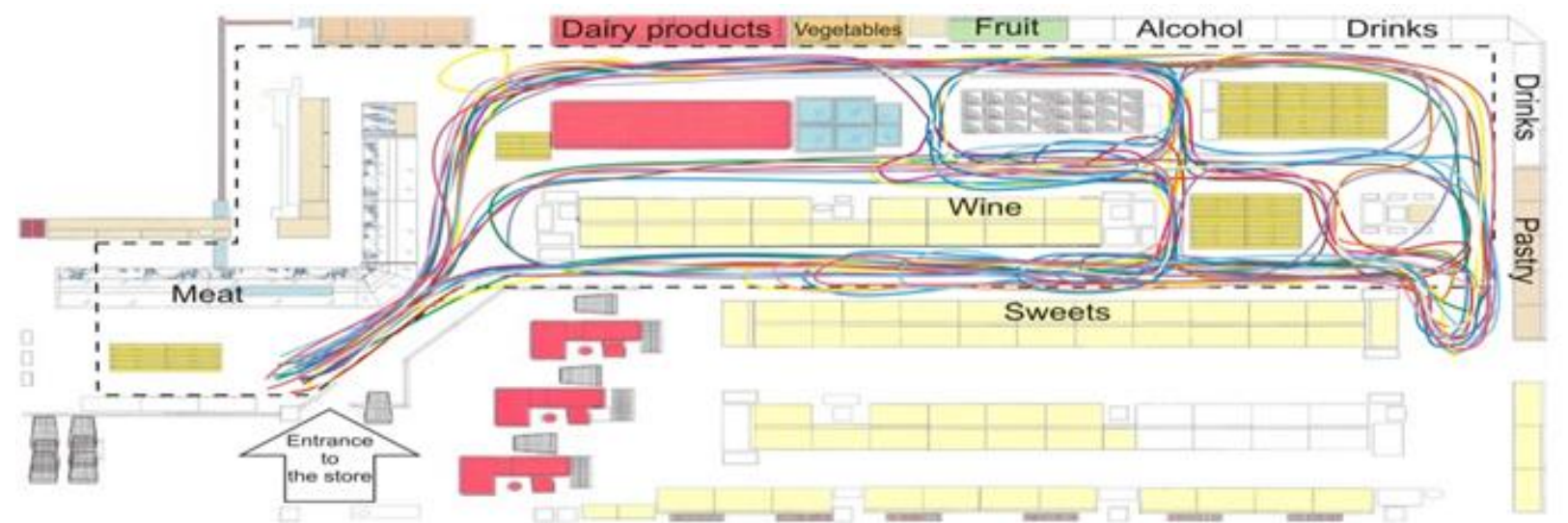

Figure 2. Movement of customers within the store layout 
The greatest concentration of customer routes within the store layout is logically in the departments where they should purchase the goods. The order of visiting particular departments was interesting. Firstly, respondents visited the department of milk and dairy produce, except two men who preferred the department of sweets. The average speed of movement of women during purchase was 2.6 $\mathrm{km} / \mathrm{h}$ while for men it was $3.4 \mathrm{~km} / \mathrm{h}$.

In addition to tracking respondents' movements in the store and neuromarketing testing, respondents were asked to fill out a short questionnaire after completion of the purchase. They had to evaluate the attractiveness of particular sales departments, as well as selected in-store marketing promotion tools placed in them. The main reason for this complementary questioning was to compare conscious and unconscious processes of the human mind. As we can see in Table 3, the most attractive tools, according to respondents' answers, are mobile panel, goods placed in free space within their sight, and audiovisual device (screen) located as well as the embroidering of goods on the shelf.

Table 3. Most attractive in-store marketing promotion tool during research in real conditions - conscious evaluation

\begin{tabular}{|l|c|c|}
\hline & Absolute frequency & Relative frequency \\
\hline Audiovisual device (screen) & 5 & $23.8 \%$ \\
\hline Arranging goods on the shelf in a row & 3 & $14.28 \%$ \\
\hline Goods placed in free space within sight & 4 & $19.05 \%$ \\
\hline Sticker on the floor & 1 & $4.80 \%$ \\
\hline Mobile panel & 6 & $28.57 \%$ \\
\hline In-store teaching sign & 2 & $9.50 \%$ \\
\hline Other & 0 & $0.00 \%$ \\
\hline Total & 21 & $100.00 \%$ \\
\hline
\end{tabular}

In fact, $28.57 \%$ participants noticed mobile panel and $23.8 \%$ participants noticed a display located on the shelf and $19.05 \%$ participants noticed goods placed in free space within sight and $14.28 \%$ participants noticed arranging goods on the shelf in a row during the purchase. We also wanted to find out which of the sales departments, visited by respondents, was the most interesting and why. An overview of individual responses can be seen in Table 4.

Table 4. Respondents 'answers to the question, which sales department they consider as the most comfortable?

\begin{tabular}{|l|c|c|}
\hline & Absolute frequency & Relative frequency \\
\hline Individual choice & 5 & $23.8 \%$ \\
\hline Milk and dairy produce & 4 & $19.05 \%$ \\
\hline Fruit and vegetables & 4 & $19.05 \%$ \\
\hline Pastry and bakery products & 3 & $14.3 \%$ \\
\hline Wine & 2 & $9.5 \%$ \\
\hline Sweets & 3 & $14.3 \%$ \\
\hline Total & 21 & $100.00 \%$ \\
\hline
\end{tabular}

It is no surprise that consumers state their own food choices as the most optimal because each of them chose such product with which he/she identifies. The department of milk and dairy produce, and fruit and vegetables was in the second place. It might be influenced by higher ambient temperatures, so the buyers felt better closer to refrigerated displays with demonstrably lower temperature than in standard sales department. The popularity of dairy produce was stated as the most common reason. As a paradox, based on the results of position system (Figure 3), customers spent the most time in the department of sweets (on 
average 32.3 seconds) where mobile panel was placed. In the wine department, they spent on an average 29.6 seconds and most of them considered screen placed on the shelf as an attractive marketing promotion tool.

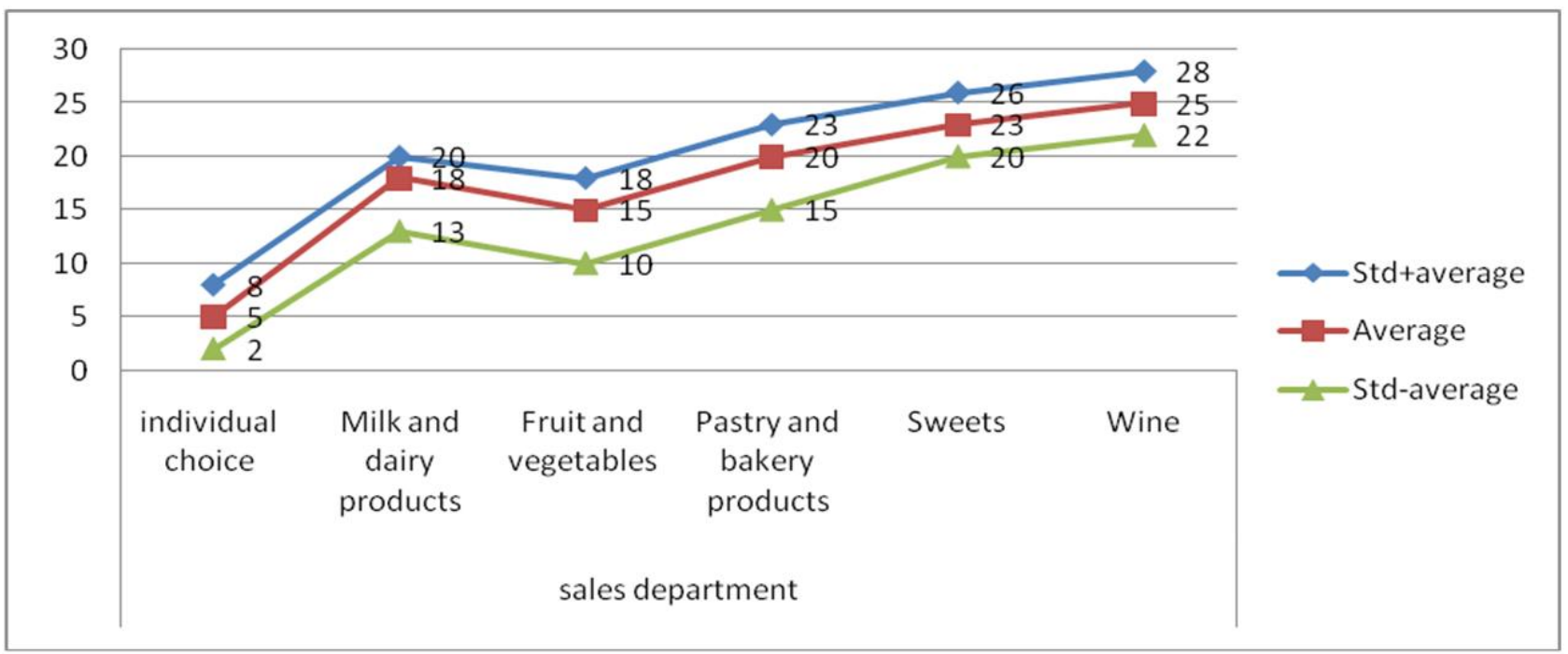

Figure 3. Time spent in particular sales departments based on position system data (Internal position system)

The tested participants spent the minimum time, on an average 5 seconds, in the department of individual choice. Figure 3 shows us a relatively wide range of values, especially in the department of wine and sweets. We can see a significant difference of times spent in these departments, mainly in terms of the customers' age. The total average time of purchases is 3 minutes 42 seconds, while for women it is 4 minutes 5 seconds and for men 3 minutes 37 seconds.
Customers most positively evaluated audiovisual device in the wine department in which they spent a relatively longer time (compared to other monitored departments). Considering this fact, we decided to verify visual attention and emotions in this sales department. The role of the display audiovisual device with LED light strip was to stimulate customers to buy red wines through a video presenting producing, storing and serving them. In Figure 4 it can be seen a display placed in close proximity to the exposure of red wines.

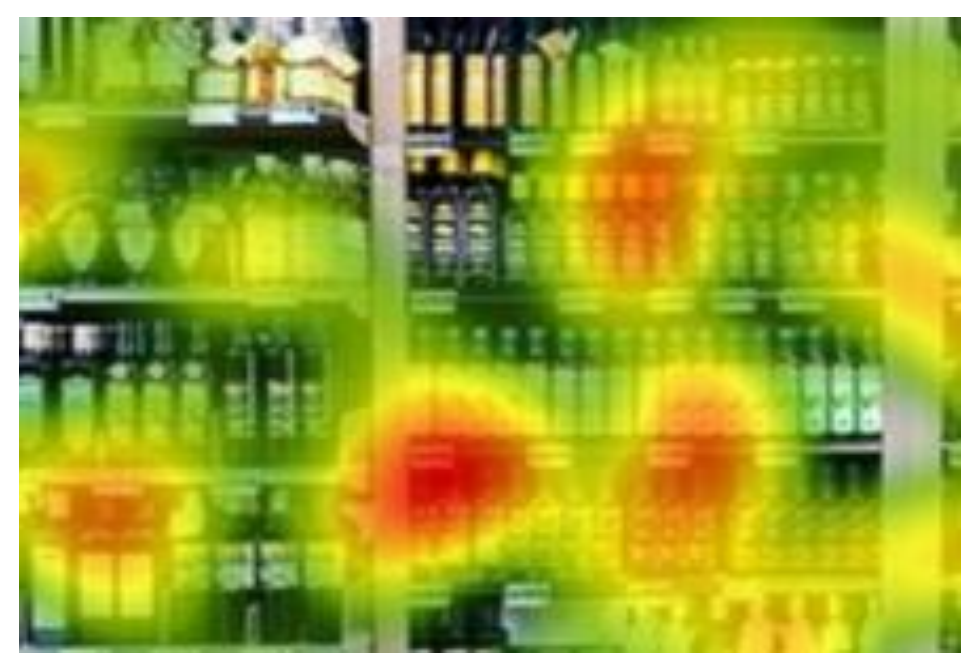

Figure 4. Heat map of the visual attention of the respondents 
Based on the processed data of mobile eye camera (Eye tracker glasses), heat map of customers' visual attention can be seen in Figure 4 too. Heat map (hotter places - red colour) shows us that consumer views were oriented not only on presentation display with LED lighting, but also on red wines or prices of them. In this case, the digital display fulfilled its purpose because consumers focused much more on red wines.

Thanks to monitoring the electrical brain activity through mobile electroencephalograph (EEG), we can observe the emotional state of participants during the purchase in the wine department (Figure 5).

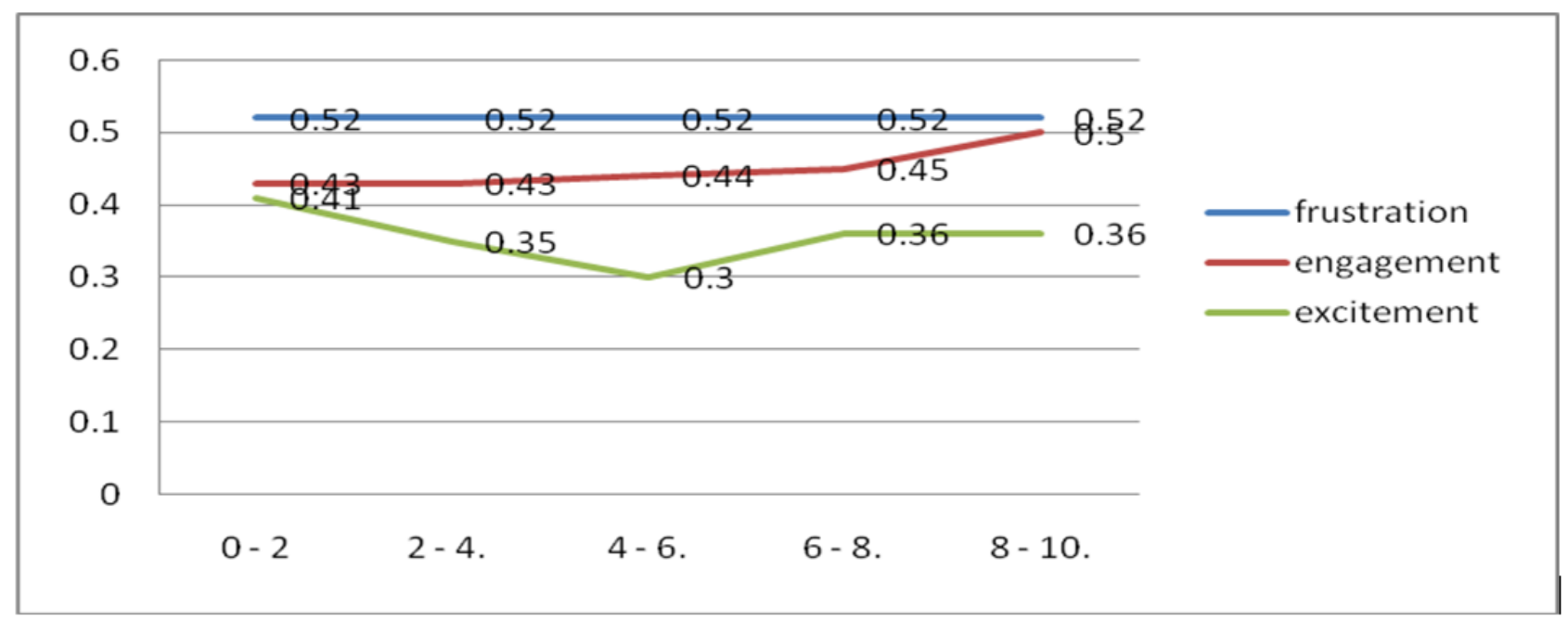

Figure 5. Medians of buyers' emotions (on audiovisual device) in wine department

The part of the monitored time period is also the respondents' view on video promotion tool with attendant effects. Emotions of frustration and emotional engagement were constant with the exception of excitement in which a significant decrease after the first two seconds was recorded. Decrease of excitement can largely be related to the interest of consumer attention in eye-catching display. Subsequent viewing of common wine exposures sensitivity to sensory stimuli is decreasing too. Figure 6 captures the average micro emotions recognized on the basis of facial expressions when viewing wines.

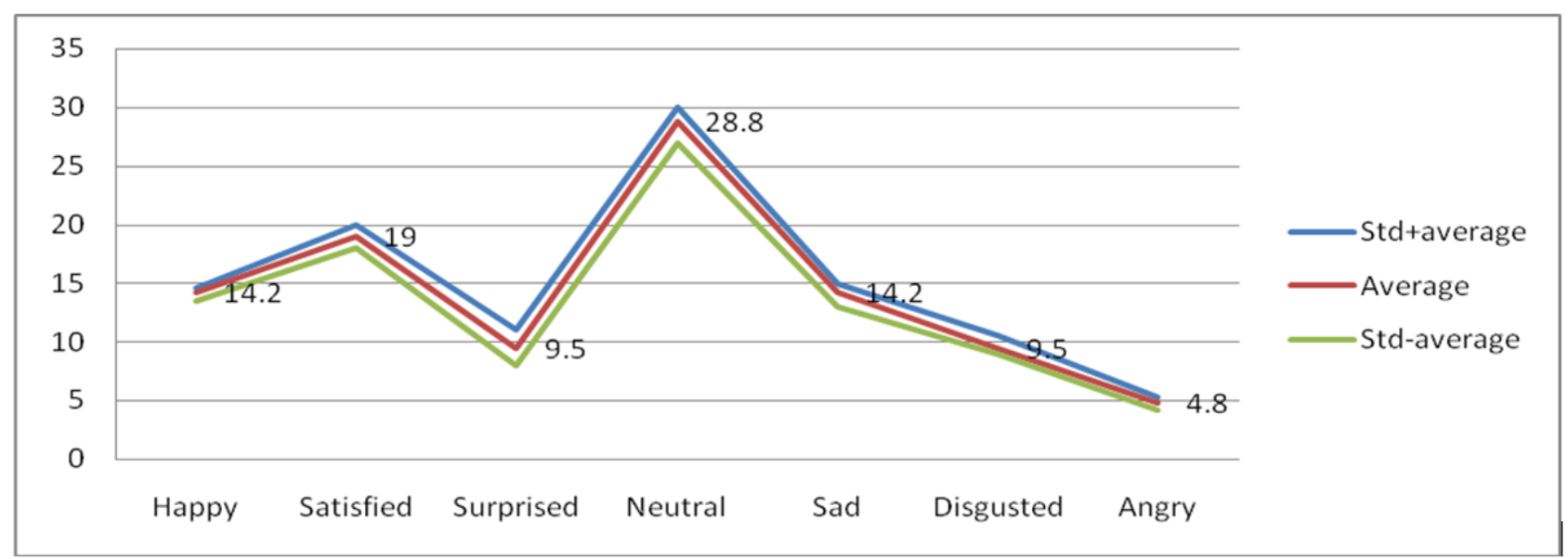

Figure 6. Recognized emotions based on facial expressions in wine sales department (Face reading)

Here we can see that the customers in this department showed $28.8 \%$ neutral emotion when selecting wines. Relatively high average values were also found in expressing happy and satisfied emotion $-33.2 \%(14.2 \%+19 \%)$ and $14.3 \%(9.5 \%+4.8 \%)$ of angry and disgusted emotion respectively. This illustrates different emotions of individually tested customers. 
Then we worked with sums and revealed that despite the small number of sample, some emotions confirmed as variable. We assume that in larger sample would be even greater fluctuations. Based on the results of customers' emotions during the purchase in sales departments we created a graph (see Figure 7).

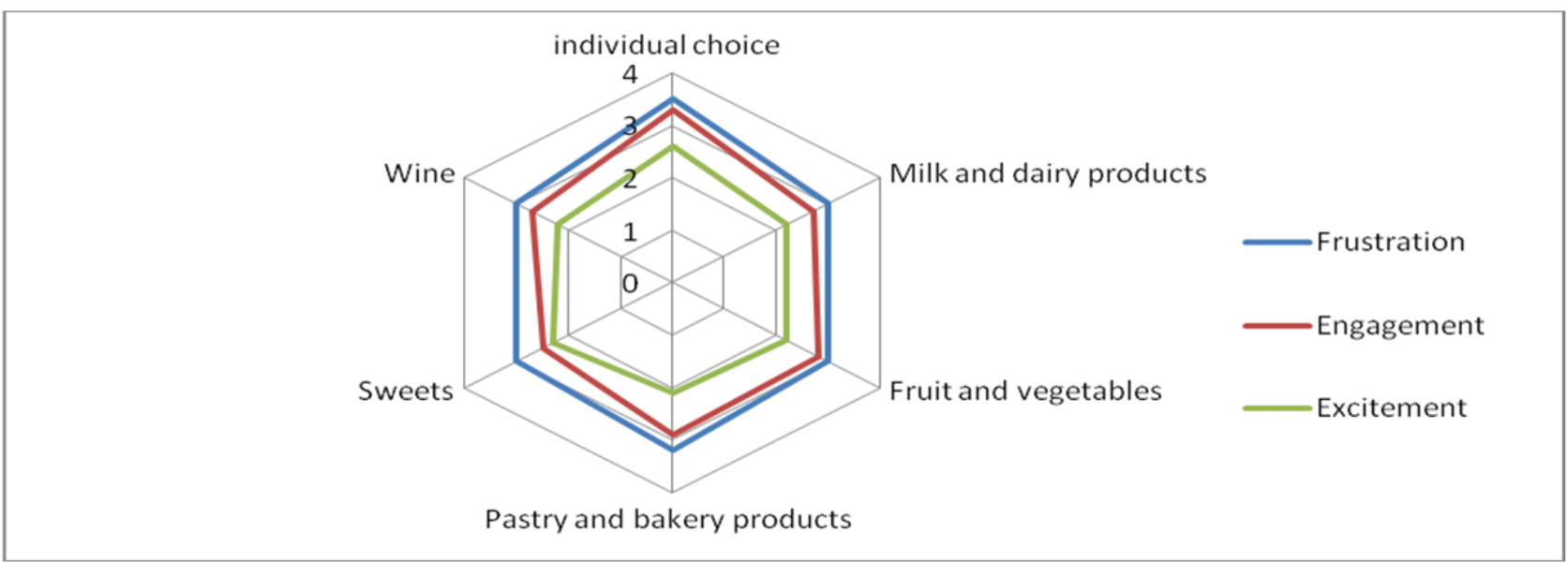

Figure 7. Comparison of perception of individual sales departments

The biggest differences between particular sales departments can be observed in emotion of excitement. During real purchase, the highest values of excitement were recorded in the department of sweets and, on the contrary, the lowest ones in the selection of pastry and bakery products. The reason could be that they are daily consumer items and this department is not attractive enough for consumers. On the other hand, emotional engagement reached the highest value just in this department. This could be caused by marketing promotion elements installed in this part of the shop (mobile panel, a display located on the shelf, goods placed in free space, the arranging goods on the shelf in a row). In the emotion of frustration, the differences in particular departments were very small. Monitoring of customers' movements, their visual attention and emotional response is an important tool in verifying the effectiveness of selected in-store marketing promotion elements within examined sales departments of a retail store. And in spite of more demanding real conditions in terms of implementation of neuromarketing testing, we proved the following:

- Despite advancements in new branches like neuroscience and neuromarketing, multiple approaches are needed in research in order to take a strong position in certain field. Besides strong scientific and technical time-consuming knowledge the need for ethical and professional understanding is next priority item to be on agenda.

- Neuromarketing research technique and equipment, including Electroencephalography (EEG), Facial expressions (FA) and Eye tracking (EOG) are very expensive and research costs are very high. However, in order to influence customer's visual attention, emotions and behaviour and irresistible desire to make a purchase, companies should optimally use instore marketing promotion tools that will lead to help customers make a right buying decision, make them satisfied with their purchase and also increase the store's sales.

- Some parts of society express concern about using latest digital technology of neuromarketing, such as EEG, FA, EOG screening human brain and nerves maintaining that such a technology threatens an individual's privacy and freedom of choice, forces customers to make a purchase and affect their choice through pushing them on and using tricks. This is the biggest and most controversial issue in neuromarketing. In today's digital age the majority of the population are able to understand their desires, interest and motivations in terms of their needs in order to better understand themselves. On the other hand, ethical use of EEG, FA, EOG 
neuromarketing methods for brain screening will be profitable for trade organizations. Wide range of good choice contributes to optimal buying decision. Making the right choice draws customer's visual attention in the right direction and activates their emotions and feelings. This will be a right solution.

- More successful entrepreneurs of highly developed markets have started to work continuously on studying consumers' brains using latest digital technologies of neuromarketing research and map out neural processes that lead to choosing goods and services by customers. In ths manner,

\section{CONCLUSIONS}

In the present paper we dealt with interdisciplinary research of in-store marketing promotion impact on visual attention, emotions and related spatial behaviour of customers in grocery stores. In-store marketing promotion tools provide the last possibility to influence the purchasing behaviour. Consequently, we focused on testing the effectiveness of selected marketing promotion tools placed in five sales departments at the point of sale. Based on the results of internal position system, we identified, with the accuracy of approximately 3 meters, spatial behaviour of customers in the reserved area. Furthermore, we determined the speed of their movement as well as times spent in monitored departments. Subsequently, we compared the times with conscious customer evaluation of these departments through a short questionnaire. Basing on their results, we conducted more detailed analysis of the impact of audiovisual device on visual attention and customers' emotions in the wine department. Based on the outputs of eye camera (Eye Tracker) and using statistical indicator (heat map) in real conditions, we proved that consumers concentrated more on places with red wines which is confirmed not only on the display but also through video footage. With mobile electroencephalograph (EEG) we recorded three emotions (frustration, engagement and excitement) during monitoring of digital device and subsequent viewing of red wines. Emotions of frustration traders/retailers are gaining some knowledge and experience by focusing on neuromarketing activities in order to achieve their goals and handle consumer behavior.

- Using purposeful neuromarketing techniques in the right manner depends only on company that exercises right neuromarketing habit. Certified monitoring organizatons should be able to control unethical and profligate behaviour on the market.

- Neuromarketing development requires conducting more market research in marketing. That would allow other companies to conduct research using abovementioned methods.

and emotional engagement were constant, except for excitement in which a significant decrease after the 4th second was recorded. Higher values may be associated with eyecatching display, which in turn decreases when viewing common wine exposures. Using the software (Face Reader 6) for recognition of micro emotions by facial expressions, we identified customer emotions during the purchase in this sales department. According to average values, it can be stated that customers felt $28.8 \%$ neutral, $14.3 \%$ angry and disgusted, and $33.2 \%$ happy and satisfied. Then we focused on the comparison of customers' emotional state in monitored sales departments. The highest values of excitement during real purchase were recorded in the department of sweets and the lowest in the selection of pastry and bakery products. Emotional engagement reached its highest value just in this department. Tracking customer movements, their visual attention and emotional response is an important tool in verifying the effectiveness of selected in-store marketing promotion elements within the departments of retail store. It allows the creation of more effective integrated marketing promotion at the point of sale. In the future, we plan to carry out a similar experiment in real conditions with a large number of respondents, taking into account accessory factors, such as weather, fatigue, seasons and phases of the week. 


\section{Limitations}

- Conducting neuromarketing research and experiments require a great deal of time, therefore, not many companies or individuals express willingness to take part in this process.

- Instability of emotions, anxiety, and uneasiness of the participants of neuromarketing experiments can often be a constraint to objective and accurate results of these experiments.

\section{REFERENCES}

1. Bárta, V., Patík, L., Postler, M. Retail marketing. Praha, CZ: Cover design, 2009.

2. Berčík, J., Paluchová, J., Kleinová, K., Horská, E., Nagyová, L. Stimulus, Space and Hidden Customers Reaction's: Applying Possibilities of Neuromarketing Research. In: International Scientific Days (ISD) 2014-21-23th of May Vysoké Tatry, Slovakia, 2014.

3. Boldbaatar, G. A neuromarketing study on Mongolian consumers' buying decision process. Journal of the Mongolian Academy of Sciences, Vol. 57, \# 04 (224), 2017.

4. Boldbaatar, G. Neuromarketing. UB, 2018.

5. Desir, K. Better Consumer Understanding through Neuromarketing in Retail. In: The Global Association for Marketing at Retail. 2014.

6. Dolley, R. Brainfluence: 100 ways to persuade and convince consumers with neuromarketing. Hoboken, NJ: John Wiley and Sons. 2012.

7. Fill, Ch. Marketing Communications: Interactivity, Communities and Content. Harlow, UK: Pearson Education Limited. 2009.

8. Genco, S., Pohlmann, A., Steidl, P. Neuromarketing for Dummies. West Sussex, UK: John Wiley \& Sons. 2013.

9. Hallbauer, S. Retail marketing and new retail idea - Marks and Spencer, Edinburg, UK: GRIN Verlag. 2008.

10. Harris, R. J., Sanborn, F. W. A Cognitive Psychology of Mass Communications. Oxford shire, UK: Routledge. 2014.

11. Holmqvist, K., Nyström, M., Andersson, R., Dewhurst, R., Jarodzka, H., Weijer, J. Eye Tracking: A comprehensive guide to methods and measures. Oxford, UK: Oxford University Press. 2011.

12. Holsanova, J. In the eye of the beholder: Visual communication from a recipient perspective. Machin, D. Visual Communication: Handbooks of Communication Science.
- Therefore, participants of the research experiment should be assisted by medical professionals in as much there are challenges in pacifying participants, convincing them of safety of the experiments and helping them to understand that their uneasiness might lead to inaccurate results of the experiment.

- Time and financial constraints limit the opportunity to broaden neuromarketing research.

Berlin, Germany: Walter De Gruyter, (Eds.), pp. 195-215, 2014.

13. Horská, E., Nagyová, L., Rovný, P. et al. Merchandising and Event Marketing: pre produkty pol'no hospodárstva. [Merchandising and Event Marketing: for Agricultural Products] Nitra, SK: SUA in Nitra. 2010.

14. Johansson, R., Holsanova, J., Homqvist, K. Pictures and Spoken Descriptions. Elicit Similar Eye Movements During Mental Imagery, both in Light and in Complete Darkness. 2006.

15. Kleinová, K. Current situation and trends in marketing research. In: Business management - practice and theory in the 21 st century. Nitra, SK: SUA in Nitra. Pp. 85-91, 2013.

16. Levine, T.R. Encyclopedia of Deception. London, UK: SAGE Publication, Ltd. 2014.

17. Loewestein, G., Risk, S., Cohen, J. Neuroeconomics. Annu Rev. Psychology. 59, 647-672, 2008.

18. Nagyová, L'., Horská, E, Kretter, A., Kubicová, L., Košičiarová, I., Récky, R., Berčík, J., Holienčinová, M. Marketing. Nitra, SK: SUA in Nitra. 2014.

19. Newman, A. J., Peter, C. Signage: Retail Marketing Operations. Journal of Management Research, 13, 264-273, 2008.

20. Popai. Better Consumer Understanding through Neuromarketing in Retail. January 23, 2014

21. Pradeep, A. The Buying Brain: Secrets for Selling to the Subconscious Mind. Washington, New Jersey: John Wiley. 2010.

22. Schiffman, L. G., Kanuk, L.L. Nákupní chování. [Consumer Behaviour]. Brno, CZ: Computer Press. 2004.

23. Shimp, T., Andrews, J. C. Advertising Promotion and Other Aspects of Integrated Marketing Communications. Mason, Ohio: Cengage Learning. 2013. 
24. Ungerleider, L. Mortimer, M. Two Cortical Visual Systems. In: Machin, D. Visual Communication: Handbooks of Communication Science. Berlin, Germany: Walter De Gruyter, (Eds.), pp. 195-215, 2014.
25. Wang, Y. J., Minor, M. Validity, reliability, and applicability of psycho-physiological techniques in marketing research. Psychology and Marketing, 25(2), pp. 197-232, 2008. 